\title{
Entre a matéria-prima e o objeto cerâmico: uma poética pessoal
}

\author{
Between the Raw Material and the Ceramic Object: \\ A Personal Poetics
}

\section{Entre la materia prima y el objeto cerámico: una poética personal}

Lorena D 'Arc Menezes de Oliveira ${ }^{1}$

http://dx.doi.org/10.22409/poiesis.1830.79-94

\begin{abstract}
RESUMO: Neste artigo abordo a minha experiência enquanto artista / professora e ceramista em relação à matéria-prima, ao utilitário doméstico e cerâmico. E discorro sobre minhas leituras a respeito dos materiais enquanto crus e cozidos em meu processo de criação.
\end{abstract}

PALAVRAS-CHAVE: artes visuais; cerâmica contemporânea; hibridismos

\footnotetext{
${ }^{1}$ Lorena D A Arc é Doutora em Artes pelo IA-UNESP, Mestra em Artes Visuais pela ECA-USP, Pós-Graduada em Arte e Contemporaneidade pela Escola Guignard, Graduada em Bacharelado e Licenciatura em Artes Plásticas pela Escola Guignard, instituição onde é professora do Departamento de Disciplinas Tridimensionais e Artes Visuais. E-mail: lorenadarc@yahoo.com.br
} 
ABSTRACT: In this article I approach my experience as an artist / teacher and ceramist in relation to the raw material, and to the domestic and ceramic utility. I discuss my readings regarding the raw and cooked materials in my process of creation.

KEYWORDS: visual arts; contemporary ceramics; hybridity

RESUMEN: En este artículo abordo mi experiencia como artista / profesora y ceramista en relación a la materia prima, la utilidad doméstica y cerámica. Discuto sobre mis lecturas acerca de los materiales mientras que crudos y cocidos en mi proceso de creación.

PALABRAS CLAVE: artes visuales; cerámica contemporánea; hibridismos

Como citar: OLIVEIRA, Lorena D Arc Menezes de. Entre a matéria-prima e o objeto cerâmico: uma poética pessoal. Poiésis, Niterói, v. 18, n. 30, p. 79-94, dez. 2017.

doi: http://dx.doi.org/10.22409/poiesis.1830.79-94

Poiésis, Niterói, v. 18, n. 30, dez. 2017. 


\title{
Entre a matéria-prima e o objeto cerâmico: uma poética pessoal
}

\author{
\{o que o barro quer\} \\ o barro \\ toma a forma \\ que você quiser \\ você nem sabe \\ estar fazendo apenas \\ o que o barro quer. \\ Paulo Leminski, 1985
}

Em 1985, quando iniciei como aluna nas aulas de modelagem e cerâmica na Escola Guignard, tive, imediatamente, uma grande identificação com a materialidade da argila e as inúmeras possibilidades do rico universo da cerâmica. Desde então, ao longo dos anos, venho me dedicando a este mundo dos argilominerais e traçando caminhos em minha prática artística.

O barro despertou em mim questões que vão além do entendimento sobre a tridimensionalidade e a espacialidade. Nele, vivo a experiência perceptiva da matéria viva, de seus sintomas e suas respostas a ações quanto ao manuseio, ao tempo de secagem, à queima; 
enfim, nele, compreendo relações fenomenológicas, semânticas e perceptivas que se instauram nas diversas instâncias e campos que abrange.

Em minha poética, muitas vezes, vejo o processo da cerâmica como um meio e não um fim, pois há uma amplidão de caminhos, cheios de possibilidades e de experimentações entre as escolhas das matérias primas, dos procedimentos técnicos de modelagem, queima e de resultados que, durante o processo do fazer, nos aponta possíveis soluções plásticas, caminhos e desdobramentos. Como professora de cerâmica, ceramista e artista visual, transito entre as bordas da cerâmica, ora como ceramista que considera os processos e os procedimentos desta arte/ciência, ora como criança que vê no barro um caminho mágico, repleto de mistérios que, muitas vezes, aponta para outros lugares e outras mídias de expressão.

Meu encantamento e meu interesse pela plasticidade e demais características da argila e argilominerais fez com que eu desenvolvesse alguns trabalhos que pudessem, de algum modo, explorar questões relacionadas à expressão da matéria-prima em si, sem ater-me somente ao ofício da cerâmica. Acredito que a influência de nascer e de viver no coração da zona mineralógica do Quadrilátero Ferrífero, me dá o privilégio de presenciar e experienciar infinitos matizes de cores e texturas de terras e óxidos de ferro. É viver em uma paleta terrosa de "montes e chão de ferro", como dizia o poeta mineiro João Guimarães Rosa (1908-1967).

Penso que em meu processo de criação, utilizar-me da matéria-prima como meio de expressão é tão importante quanto utilizá-la para produzir uma massa para uma modelagem. Sempre busquei explorar a essência dos materiais naturais de forma mais intuitiva, perceber as sensações, as memórias ou o seu caráter simbólico. Tudo no material me interessa, e constato isso nas palavras da artista visual Elisa Campos Amaral:

além dessas qualidades físicas que se pode apreender do material, outras qualidades podem ser observadas. Os elementos que despertam os sentidos num apelo à percepção através de sua sensualidade ou re-

Poiésis, Niterói, v. 18, n. 30, dez. 2017. 
pulsa, de qualidades que provocam memórias ou novas sensações, de uma aparência a se diferenciar na medida de seu distanciamento. (AMARAL, 2001, p. 61)

Com o tempo, fui compreendendo a dimensão e a potência que os materiais naturais suscitam e como eles consolidam uma ideia em uma produção artística, na precisão de suas composições e propriedades, e nos desígnios de suas essências e aplicabilidades.

Assim, em consonância às questões relacionadas entre o efêmero e o duradouro, como a argila crua ou cozida, percebo na fala de Herbert Read indicações nesse sentido, quando relaciona a cosmologia chinesa, do Ser e Não Ser, ao mistério do aparecimento da forma a partir de um caos primordial:

Esse processo de formação, de reunião de contrários, um logos, permanece no nível cosmológico no pensamento chinês, mas o processo não termina com a água, os rios, o solo e a poeira, estendendo-se, por analogia, às plantas e animais vivos, e finalmente até a raça humana e seus artefatos. A obra de arte é concebida como um símbolo de unidades cósmicas, como uma reificação das essências concentradas do ying e yang. (READ, 1981, p. 88)

Trabalhar com os contrastes do barro como material cru e a cerâmica como material cozido possibilitou-me legitimar a forma como Heidegger reconheceu pertencer à essência mesma do ser, quando diz: "O ser (Sein) é aquilo que alcança um limite por si mesmo. Aquilo que se coloca no seu limite, completando-se, e assim permanece, tem forma, morphe. Forma, como os gregos a entendem, deriva sua essência de um incipiente 'colocarse-no-limite'". (READ, 1981, p. 83)

Este limite implicado entre as bordas da cerâmica, que deriva entre a forma das essências crua e cozida, é um lugar importante dentro da construção de meu repertório artístico, pois dialoga com a materialidade, a temporalidade e a transitoriedade das coisas. No início de minha trajetória artística, nas duas primeiras exposições individuais, apresentei pequenas instalações que utilizei, além da cerâmica, outros materiais cerâmicos crus, como o caulim e óxido de ferro. 
Em 1989, apresentei no Centro Cultural da UFMG uma pequena instalação intitulada $\mathrm{Na}$ trilha (Figs. 1 e 2), que consistia em um caminho de caulim no chão da galeria, como se fosse um tapete branco e, ao longo desse caminho, foram dispostos oito vasos de terracota embocados para baixo. Em cada orifício no fundo de cada vaso era encaixada uma rosa natural que estava congelada na água no formato de redomas. Entre o tapete de argila crua e o vaso queimado, dispus uma considerável quantidade de óxido de ferro vermelho oculto no interior de cada vaso. À medida que a redoma de gelo descongelava, a rosa vermelha se desvelava e a água advinda deste processo de descongelamento perpassava entre o vaso de terracota e a trilha de caulim, gerando fendas vermelhas que se abriam no tapete branco. As manchas e as trilhas que fluíram no caulim, ao longo da exposição, foram se modificando ao secarem juntamente com as rosas. Esses devires da ação do tempo, atuando sobre as matérias orgânicas e inorgânicas da pequena instalação, propiciaram transformações distintas que me despertaram a desenvolver outros desdobramentos.

A partir da observação e do encantamento pelo derrame do óxido de ferro e de sua reação junto ao caulim na instalação Na trilha, desenvolvi o trabalho Cadê a água? (Figs. 3, 4 e 5), que apresentei no ano seguinte, na Galeria do Palácio das Artes em Belo Horizonte. Como boa mineira que sou, por ter o hábito de falar no ímpeto, reduzindo as palavras quase que pela metade, Cadê a água? refere-se à linguagem informal mineira. Os elementos utilizados neste trabalho são praticamente os mesmos de Na trilha, exceto o tripé de ferro e o coador feito de tule. Na abertura da exposição, lancei, dentro do coador, pedras de gelo que continham pétalas de rosas dentro e, em virtude do derretimento do gelo, e de seu gotejamento, faziam com que a água do desgelo caísse sobre o caulim, perfurando a camada branca que cuspia gotas vermelhas de óxido de ferro.

Na medida em que o tempo passava, a poça d’água vermelha formada pelo gotejamento do desgelo no centro do caulim abria-se em uma grande mancha que desidratava no decorrer da exposição. Este processo despertava a curiosidade de quem não acompanhara a ação desde o seu início, e certo estranhamento pelas pétalas de rosa do desgelo que secavam no coador de tule.

Poiésis, Niterói, v. 18, n. 30, dez. 2017. 

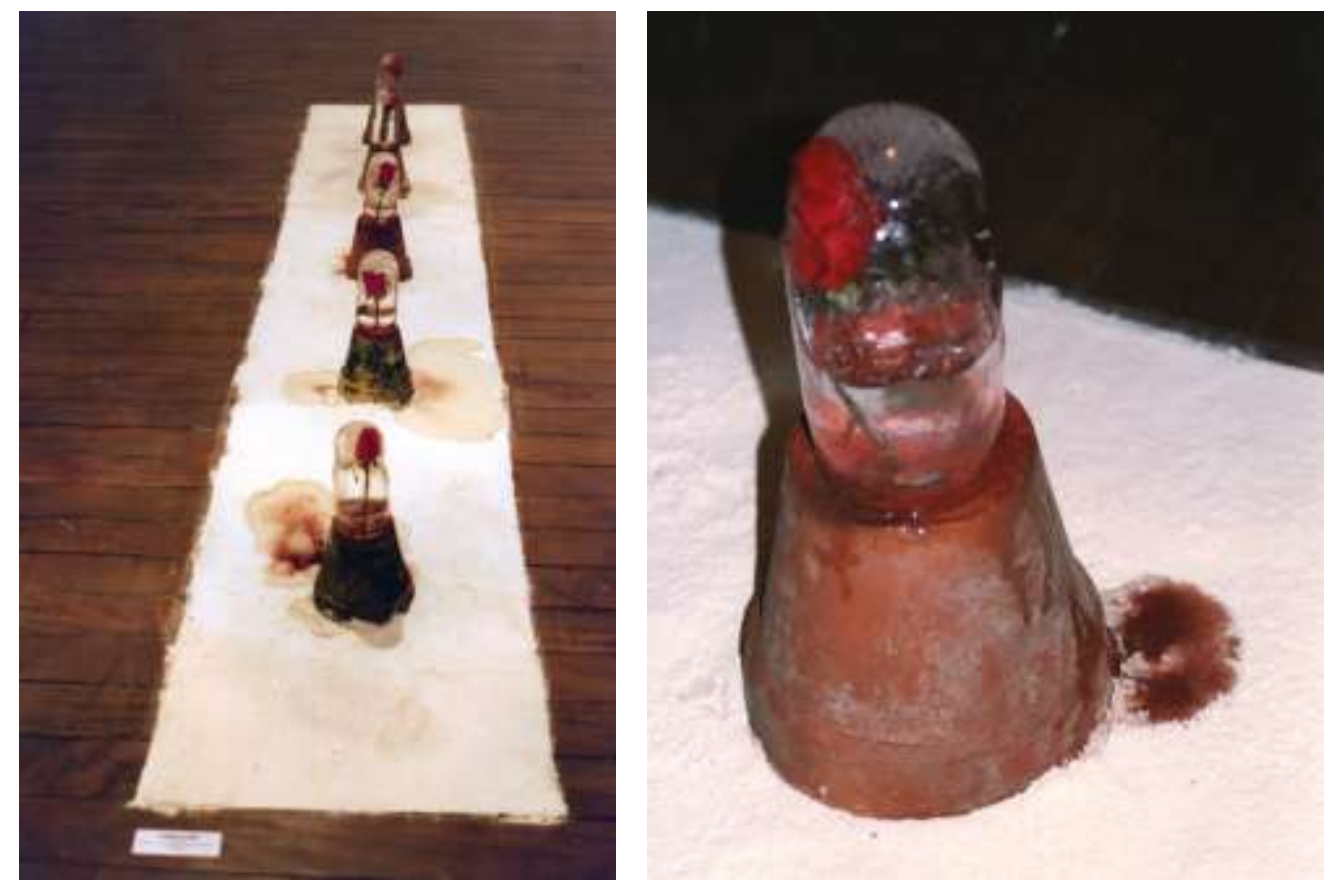

Figs. 1 e 2 - Lorena D'Arc, Na trilha, 1998.

instalação (cerâmica, gelo, óxido de ferro, caulim), 40 × 60 × $400 \mathrm{~cm}$

(Fotos: Tibério França)

Poiésis, Niterói, v. 18, n. 30, dez. 2017. 

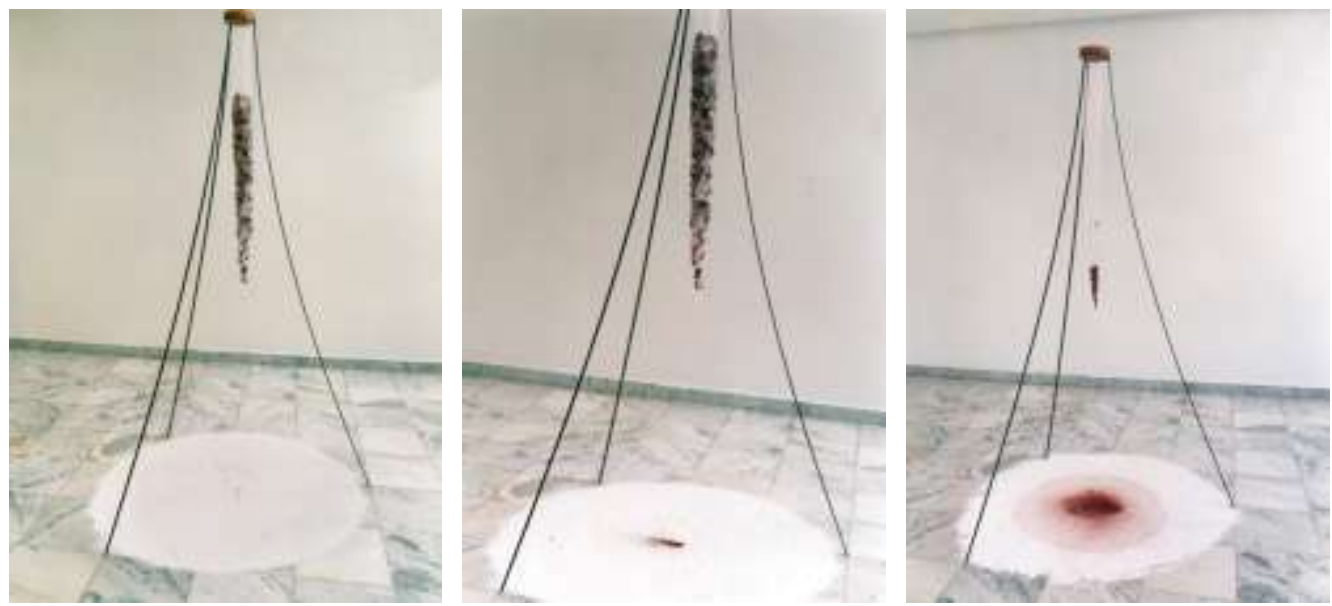

Figs. 3, 4 e 5 - Lorena D 'Arc. Cadê a água?, 1999.

vergalhão de ferro, cerâmica, tule, gelo com pétalas de rosa, óxido de ferro e caulim, $250 \times 100 \times 100 \mathrm{~cm}$

(Foto: Tibério França)

Poiésis, Niterói, v. 18, n. 30, dez. 2017. 
Com a vontade de eternizar a performance e a força expressiva das matérias durante o período da exibição do trabalho Cadê a água?, resolvi capturar essa passagem efêmera em vídeo, o que culminou na produção do Vídeo-pintura (Figs. 6, 7, 8 e 9), selecionado em 2001 no I Salão Cataguazes - Leopoldina de Artes Visuais, exposto em uma sala especial.

As imagens em câmera fixa para a produção do Vídeo-pintura compreendem somente na ação do gotejamento da água sobre o caulim polvilhado que camufla o óxido de ferro. A poética do vídeo é marcada pela expressividade dos argilominerais por meio da varredura do tempo, tendo como interface o suporte virtual para explorar a metamorfose das matérias, do lugar e do tempo, numa em uma síntese de um conjunto de formas em mutação.

Vejo na produção desses trabalhos uma proximidade à proposta de Lévi-Strauss (19082009) em seu livro o cru e o cozido, em que o antropólogo procura transcender a oposição entre o sensível e o inteligível. O sensível seria como um entendimento de primeira ordem, proveniente da percepção e da experiência, já o inteligível, como uma ciência de segunda ordem, ou seja, seria o olhar sobre as significações do que se tem entendimento. (Lévi-Strauss, 1991) Nesta vertente, percebo uma afinidade com o pensamento de LéviStrauss nos trabalhos Na trilha e Cadê a água?, nos quais há uma relação direta do espectador com a matéria-prima que, em primeira ordem, estaria relacionada à percepção, à experiência do sensível e seus desdobramentos naturais, como ouvir uma música pela primeira vez. Dessa experiência vivenciada durante sua exibição, despertei-me para criar - Vídeo-Pintura, que registra as passagens do tempo efetivamente no trabalho Cadê a água?, mas que seria uma outra compreensão da ação do tempo sobre as matérias, um entendimento de segunda ordem, de uma leitura inteligível, como a partitura musical apontada por Lévi-Strauss, a partitura que registra a música e possibilita sua repetição fidedigna.

Tratar os materiais cerâmicos, as matérias-primas e manufaturados, dentro e fora do contexto da feitura da cerâmica, sempre foi de grande interesse e uma constante em minha produção. Ao buscar relações entre as bordas da cerâmica e outros materiais, 

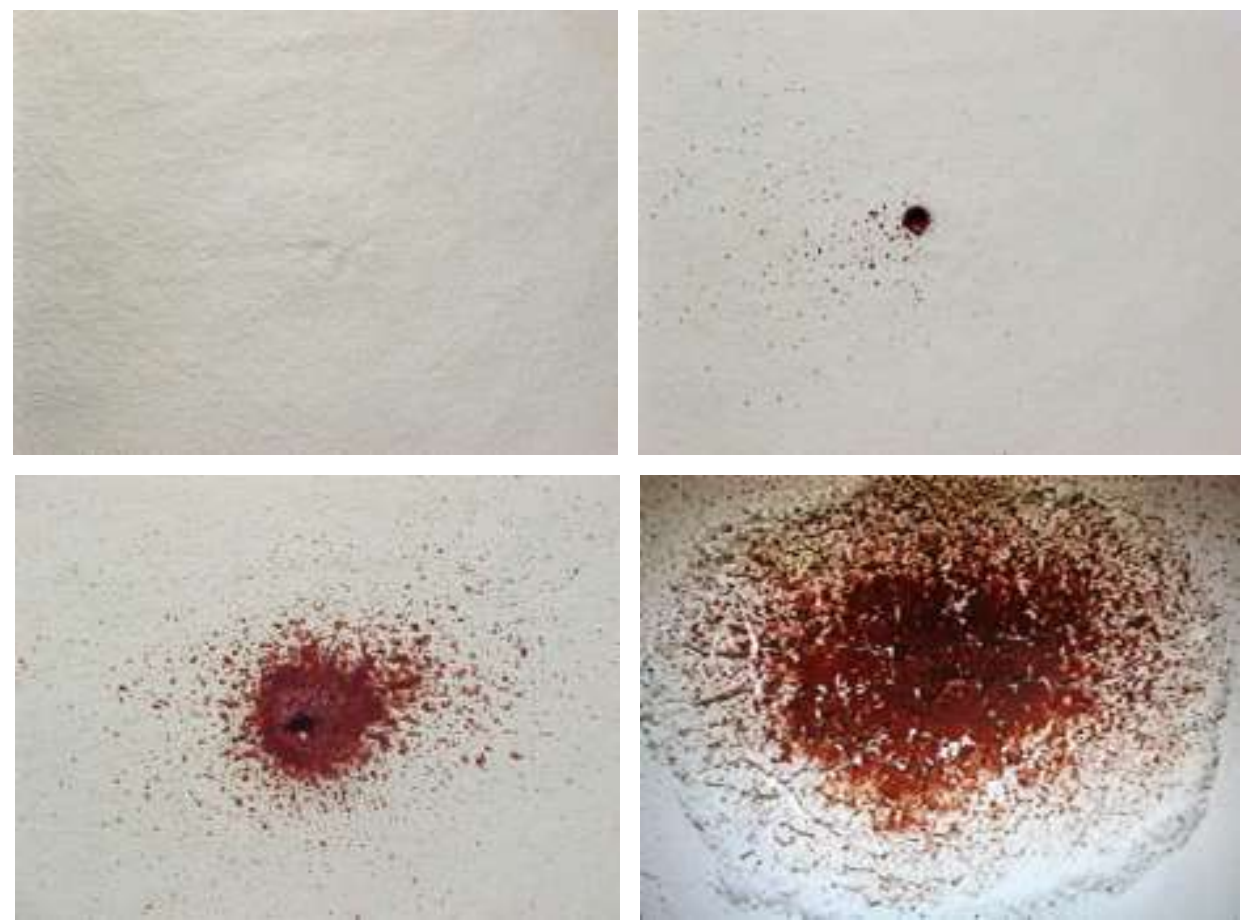

Figs. 6, 7, 8 e 9 - Lorena D 'Arc,. Vídeo-pintura, 2001.

vídeo, $2 \mathrm{~m} 38 \mathrm{~s}$ (frames)

(Imagens: Flander de Souza)

Poiésis, Niterói, v. 18, n. 30, dez. 2017. 
descubro novos caminhos em minha poética e estabeleço novas pontes entre as mídias experimentadas, logrando, em alguns momentos, para trabalhos que se entrecruzam entre o arcaico, o tradicional e o contemporâneo.

Sobre minha produção em cerâmica, em 2007, realizei a exposição Inutilitários na Galeria de Arte do Fórum de Belo Horizonte, apresentando uma série de porcelanas. Esta mostra individual tinha como proposta destituir a função do utilitário cerâmico, por meio de procedimentos incorporados a outros materiais, como tripas, peles e plumagens. Interessam-me os contrastes da superfície refratária e inorgânica da porcelana branca, fria, lisa, em oposição à porosidade da pele orgânica, macia e, por vez, repulsiva. Vazio entre nós (Fig. 10) ilustra esta minha pesquisa, na composição de duas garrafas de forma clássica, sendo uma em porcelana vitrificada e outra em grés cru; as duas peças são unidas por uma trama de tricô que as encobre até a metade. Para realizar o tricô de tripa de porco, uni as tripas por meio de nós com a finalidade de tecer a trama. Interessam-me as técnicas primitivas do tecer e do modelar, técnicas que nasceram nos primórdios da humanidade e que acompanham a evolução tecnológica de cada tempo.

Ao meu ver, tanto a cerâmica cozida quanto a trama crua da tripa de porco dialogam entre o sensível e o inteligível, no sentido de pertencerem à leitura simbólica do vazio existente entre nós, além de reportarem ao fazer manual, à matéria-prima, bruta e manufaturada. Neste trabalho, teço, entre o utilitário cerâmico e o alimento, relações presentes no universo feminino e na prática do cozinhar, desviados de suas funções habituais, como matérias plásticas, estéticas e conceituais.

A cozinha me inspira em suas histórias, memórias e vasilhames. Entre 2004 e 2007, mantive um ateliê no Bairro Santo Antônio em Belo Horizonte. Nesse espaço, realizava minha produção e dava aulas semanais de cerâmica. Os alunos desenvolviam seus projetos pessoais e discutíamos, como bons mineiros, em volta da mesa de lanche, no intervalo das aulas

Para fazer o café dessas pequenas pausas, ganhei uma chaleira de alumínio antiga, que estava guardada há alguns anos e que fora de minha bisavó, Dona Santinha. Chaleira 
herdada de uma bisavó com nome de santa, para mim só poderia significar algo ligado ao sagrado!

Ao utilizar minha vasilha herdada, constatei que, por melhor que fizesse uma chaleira, nenhuma se equivaleria, em termos sentimentais, ao valor daquela herdada por minha bisavó. A simples chaleira de alumínio me reporta às boas lembranças da infância, sentada à mesa de sua casa.

Ao aliar a funcionalidade e a memória afetiva da chaleira da bisa Santinha, resolvi mantêla em sua utilidade e parti para a produção de uma chaleira mais descompromissada de uso. Afinal, o meu interesse na cerâmica sempre foi mais voltado para o caráter da matéria-prima e a construção tridimensional ao invés da produção utilitária. Vejo o utilitário em minha produção, como o poeta mato-grossense Manuel de Barros (1916-2014) apresenta seus objetos do cotidiano, de forma descoisificada. Em seus poemas, como "por exemplo, dar ao pente funções de não pentear", busco referências para criar Chaleirisse (Fig. 11) e realizar o meu exercício de descoisificar utensílios.

Por estar envolvida com questões referentes à desfuncionalização do utilitário cerâmico, parti com esse propósito de modelar um objeto cerâmico que não tivesse compromisso com sua função utilitária e, desse pensamento, excedi na quantidade dos bicos da chaleira.

Ao ver a superabundância de seus 20 bicos, reportei-me à generosidade do seio familiar e à alegria do aconchego materno, sentimentos que sempre estiveram disponíveis e em oferta na cozinha de casa.

Apesar da fartura dos bicos, a alça, tecida em tripa de porco, alude à precariedade do alimento que é aparentemente frágil e mole. Seu contraste, em relação ao corpo da porcelana, representa a resistência que se obtém ao tecer uma trama, mesmo usando um material tão insólito. Contudo, os dois corpos foram tecidos em tramas orgânica e inorgânica. As laçadas do tricô de tripa de porco comportam-se como os rolinhos de barro, que se moldam na construção de um tecido seja de barro ou de pele, mas que ganham resis-

Poiésis, Niterói, v. 18, n. 30, dez. 2017. 


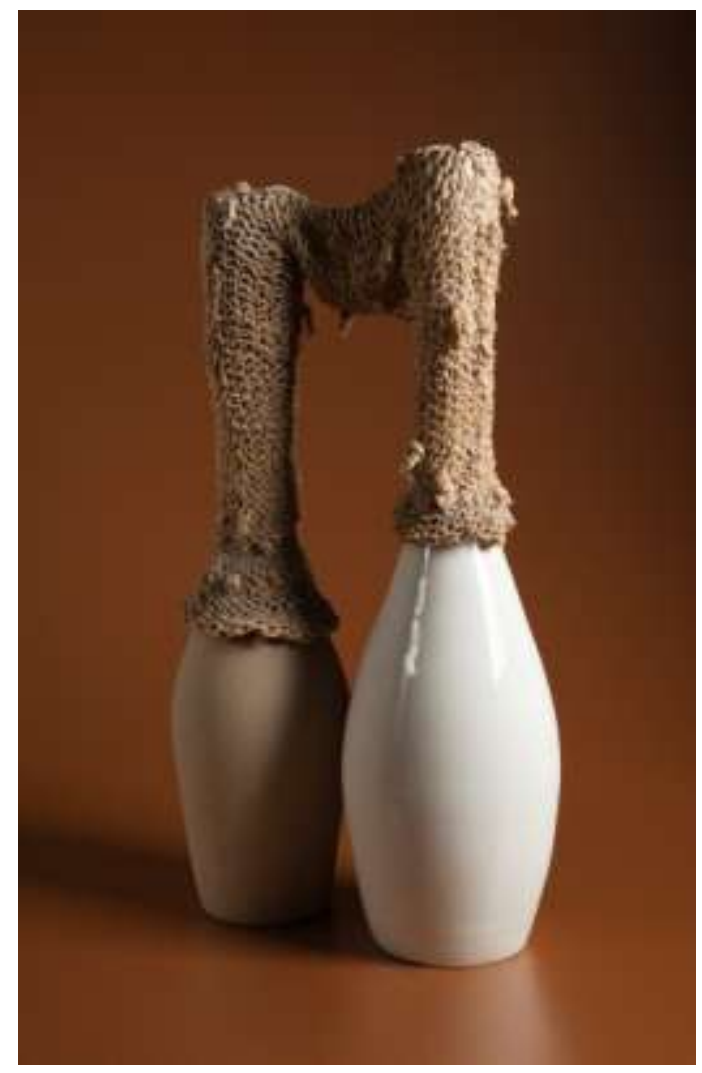

Fig. 10 - Lorena D 'Arc, Vazio entre nós, 2007.

cerâmica e tricô de tripa de porco

(Foto: Miguel Aun)

Poiésis, Niterói, v. 18, n. 30, dez. 2017. 


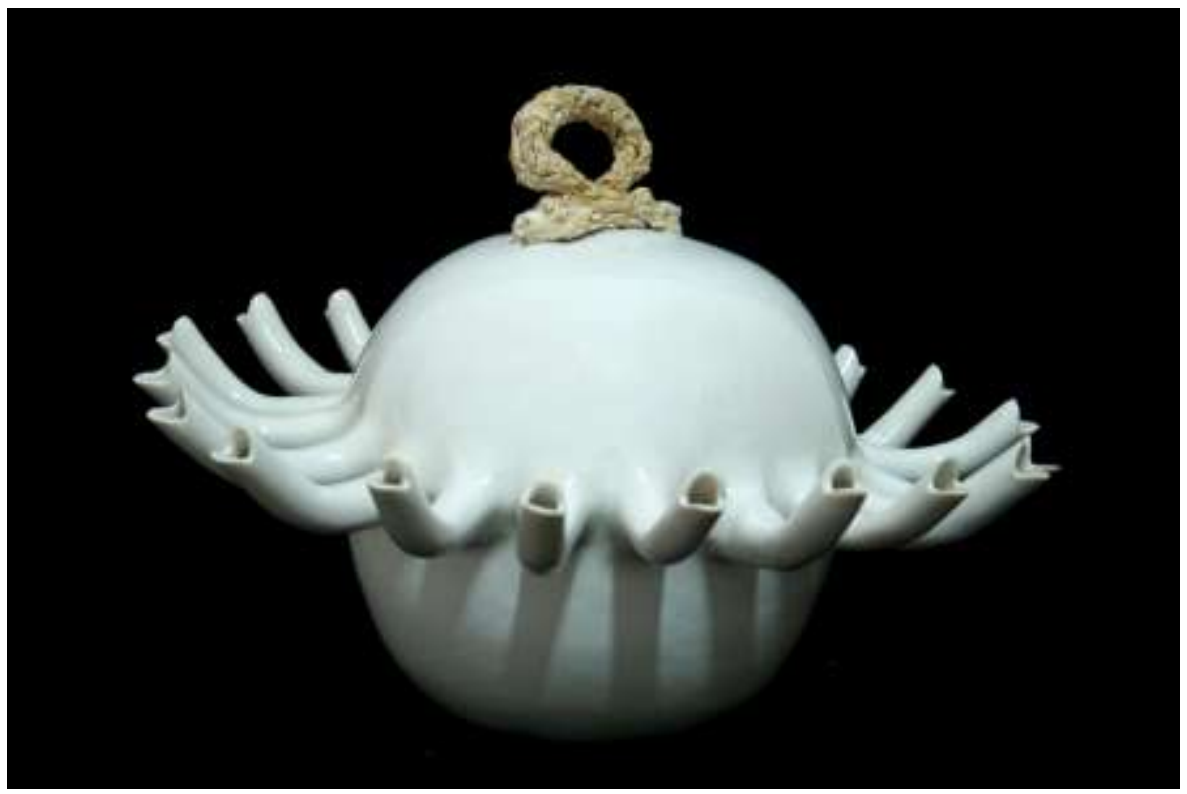

Fig. 11 - Lorena D 'Arc, Chaleirisse, 2007.

porcelana e tricô de tripa de porco, $24 \times 40 \varnothing \mathrm{cm}$

Teapot Museum, Shangai, China

(Foto: Samuca Martins)

Poiésis, Niterói, v. 18, n. 30, dez. 2017. 
tência enquanto trama. Ao tratar sobre a imaginação material, Bachelard aponta para a imaginação que se alimenta de uma vontade transformadora da matéria, na verdade, as imaginações material e dinâmica, em consonância com a vontade de criar. Sobre a imaginação das forças em A Terra e os Devaneios da Vontade, o autor, ao considerar o elemento terra, discute sobre a conscientização dos devires entre as matérias duras e moles e suas forças intervenientes:

pelas matérias duras e pelas matérias moles que tomamos consciência de nossas próprias potências dinâmicas, e de suas variedades, de suas contradições. Através do duro e do mole aprendemos a pluralidade dos devires, percebendo provas bem diferentes da eficácia do tempo. (BACHELARD, 2001, p. 16)

Desse processo entre o duro e o mole, da argila crua e queimada e da tripa fresca e desidratada, e seus contrastres hápticos, testemunho camadas, espessuras, tempos e respostas diferentes.

Em minha produção, o meu interesse parte da vontade de articular o utensílio fora de sua aplicabilidade ou de seu contexto original. Faço o exercício de "descoisificar" a louça de cada dia, na tentativa de singularizar o que a indústria banalizou. Por meio da prática ou operação artística, relaciono minhas memórias e meu encantamento pelos materiais, prezando o valor simbólico do material e o seu caráter enquanto matéria-prima. Dentro deste contexto, percebo nos desdobramentos do utilitário e de suas matérias-primas, o desvelamento de memórias instauradas tanto nos objetos domésticos, quanto nos materiais que o compõe. Ao experienciar este universo que comunga o barro, compreendo entre as bordas da cerâmica, entre a matéria e o objeto, um lugar para a pesquisa de si, do entorno e a reflexão. 


\section{Referências}

AMARAL, M. E. M. C. Clivagens da matéria: uma abordagem nas artes plásticas. Dissertação (Mestrado em Artes, Escola de Belas Artes, UFMG), 2001. 367f.

BACHELARD, G. A terra e os devaneios da vontade: ensaio sobre a imaginação das forças. São Paulo: Martins Fontes, 2001.

BARROS, M. O livro das ignorãças. Rio de Janeiro: Record, 2009.

LEMINSKI, P. Caprichos e Relaxos. São Paulo: Editora Brasiliense, 1985.

LÉVI-STRAUS, C. O cru e o cozido. São Paulo: Brasiliense, 1991.

READ, H. As origens da forma da arte. Rio de Janeiro: ZAHAR, 1981.

GUIMARÃES ROSA, J. O Cruzeiro [revista], Rio de Janeiro, Diários Associados de Assis Chateaubriand, 25/8/1957. 